\title{
Dinâmica da série nitrogenada nas águas da bacia hidrográfica Apodi/Mossoró - RN - Brasil
}

Thiago Mielle Brito Ferreira Oliveira, Luiz Di Souza e Suely Souza Leal de Castro*

Departamento de Química, Faculdade de Ciências Exatas e Naturais, Universidade do Estado do Rio Grande do Norte, CEP 59610-090, Mossoró, RN, Brasil.*suelycastro@uern.br

Resumo: A bacia hidrográfica Apodi/Mossoró é um dos mais importantes recursos hídricos do Rio Grande do Norte. Estudos recentes mostraram que os compostos nitrogenados destacam-se entre os principais contaminantes deste corpo aquático, mostrando a necessidade de relacionálos com outras propriedades físico-químicas que influenciam na dinâmica das suas formas. Deste modo, este trabalho tem por objetivo correlacionar as concentrações de $\mathrm{NO}_{3}^{-}, \mathrm{NO}_{2}^{-}$e $\mathrm{NH}_{3}$ com os valores de $\mathrm{pH}, \mathrm{T}$, Eh e OD nas águas desta bacia. Os resultados indicam o predomínio de um meio fortemente oxidante, destacando o $\mathrm{NO}_{3}^{-}$como a principal forma de nitrogênio presente, mesmo nos locais onde foram observadas reduções significativas de Eh e OD. Este trabalho busca contribuir para o desenvolvimento de medidas de controle e manejo das fontes poluidoras e o melhor gerenciamento deste recurso hídrico.

Palavras-chave: Rio Apodi/Mossoró, eutrofização, propriedades físico-químicas, nitrogênio, água.

\section{INTRODUÇÃO}

A falta de um planejamento sustentável, durante o processo de ocupação do solo, intensificada no Brasil a partir da década de 60, acarretou sérios impactos à sociedade como um todo, devido aos diversos desequilíbrios ambientais ocasionados, a exemplo da contaminação dos recursos hídricos, constituindo uma forte ameaça à economia nacional, bem como à saúde pública.

A bacia hidrográfica do rio Apodi/Mossoró (Figura 1), localizada na região oeste do estado do Rio Grande do Norte (RN) é um exemplo típico deste problema. Com uma área de $14.276 \mathrm{~km}^{2}$, equivalente a $26,8 \%$ da área estimada do Estado, representa a maior bacia hidrográfica genuinamente potiguar. São cadastrados 618 açudes, totalizando um volume de $469.714 .600 \mathrm{~m}^{3}$ de água, o que corresponde, respectivamente, a $27,4 \%$ e $10,7 \%$ do total de açudes e volumes acumulados no RN. Seu rio principal possui $210 \mathrm{~km}$ de extensão, nascente no município de Luis Gomes e foz no Oceano Atlântico, onde abriga uma planície litorânea, na forma de estuário, entre os municípios de Areia Branca e Grossos. A vazão é de aproximadamente 360 milhões $\mathrm{de}^{3} / \mathrm{ano}$, com o escoamento iniciando no mês de fevereiro e diminuindo drasticamente a partir do mês de junho, tornando-se praticamente nulo nos meses de novembro e dezembro. Isto se deve ao clima semiárido da região, que favorece os altos índices de evaporação e à escassez de água, conforme dados pluviométricos de alguns municípios distribuídos ao longo da bacia (Figura 2). 


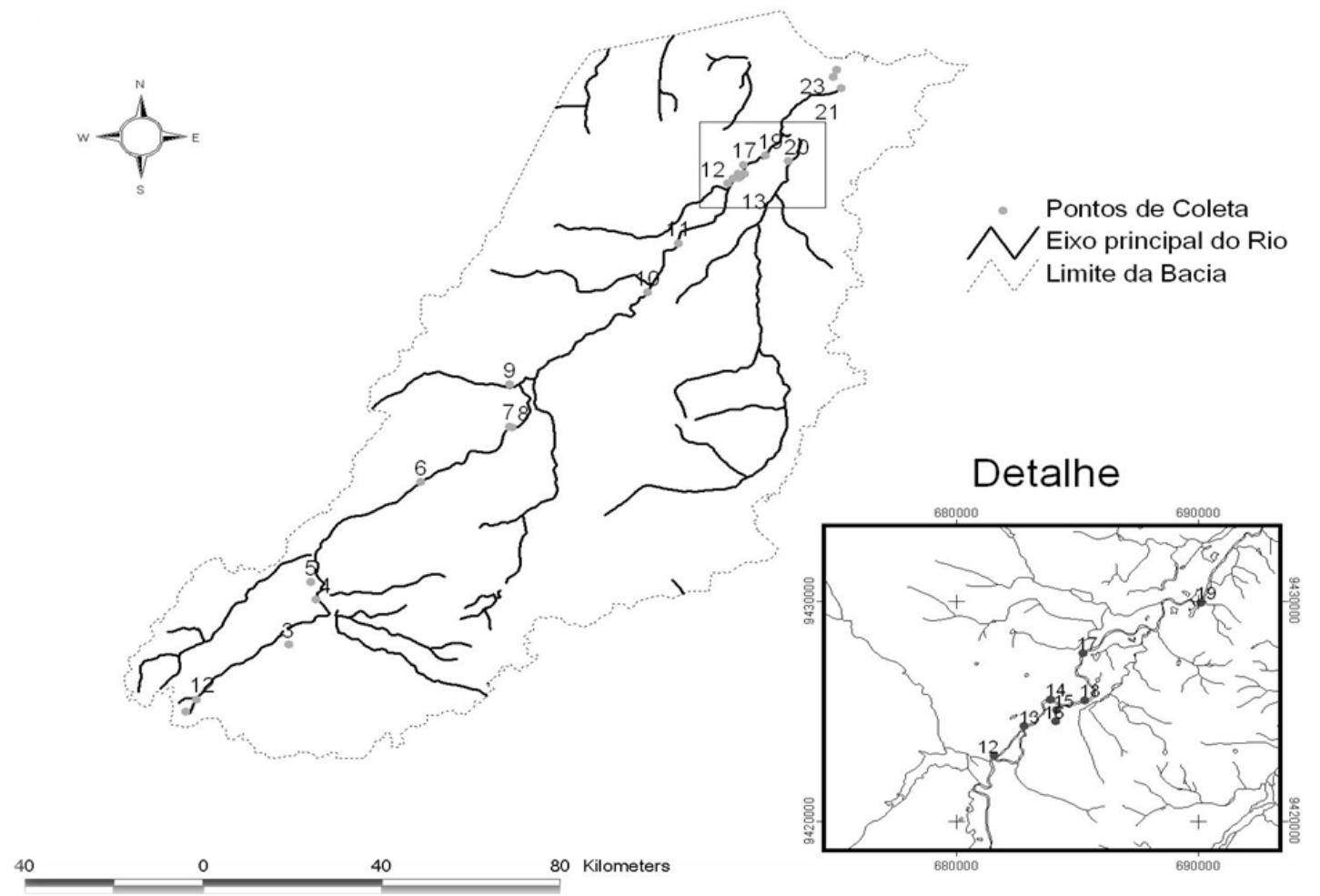

Figura 1 - Estações de amostragem na Bacia Hidrográfica Apodi/Mossoró. O detalhe refere-se à região urbana do município de Mossoró/RN. 


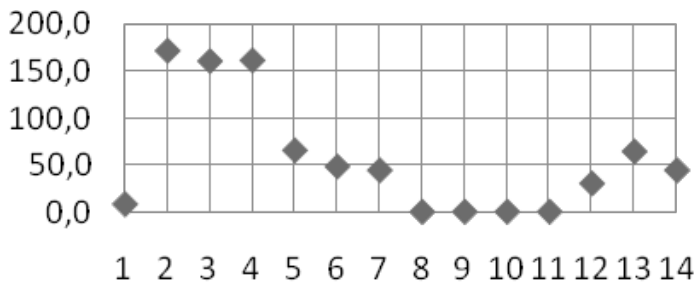

(A)

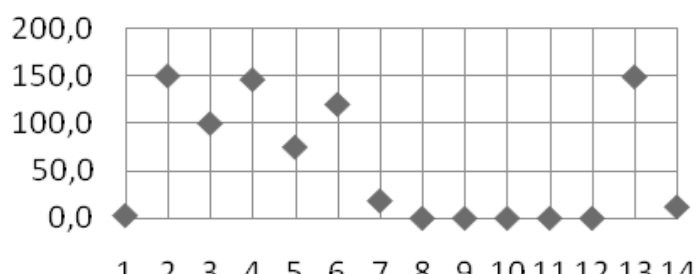

(C)

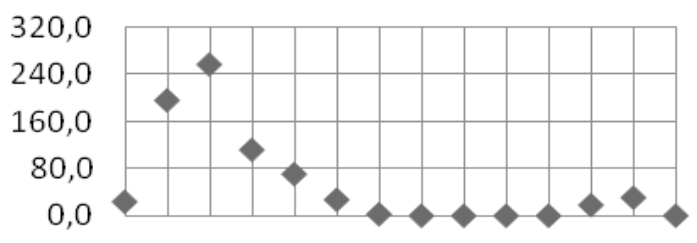

$\begin{array}{llllllllll}1 & 2 & 3 & 4 & 5 & 6 & 7 & 8 & 9 & 1011121314\end{array}$

(E)

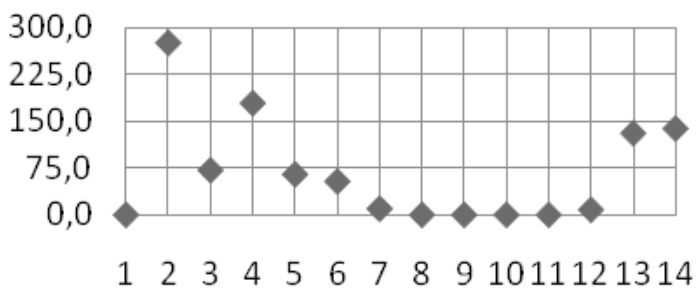

(B)

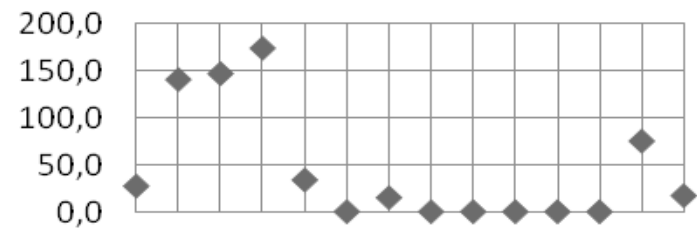

$\begin{array}{llllllllll}1 & 2 & 3 & 4 & 5 & 6 & 7 & 8 & 9 & 1011121314\end{array}$

(D)

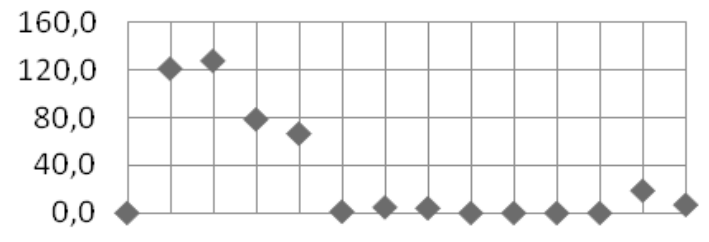

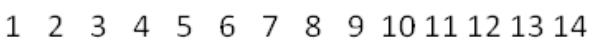

(F)

\section{FONTE: EMPARN}

Figura 2 - Precipitação pluviométrica nas cidades de Luis Gomes (A), Pau dos Ferros (B), Apodi (C), Governados Dix-Sept Rosado (D), Mossoró (E) e Areia Branca (F), no período de janeiro de 2007 a fevereiro de 2008.

Apesar de sua importância sócio-econômica, a bacia hidrográfica vem sofrendo constantes impactos, provenientes da lixiviação de fertilizantes e pesticidas das diversas atividades agrícolas desenvolvidas no entorno do rio; carreamento de material alóctone; além das constantes descargas de esgotos domésticos e industriais lançados em toda a extensão da bacia.

Rebouças e colaboradores [2] destacam, dentre 24 bacias hidrográficas do Nordeste, a bacia hidrográfica Apodi/Mossoró como predisposta a situações críticas em sua sustentabilidade, quando são considerados o acesso, disponibilidade, armazenamento de água e o aporte de contaminantes, baseando-se em um estudo de tendências entre os anos de 1991 a 2020, em relação ao Índice de Regularidade Fluvial, Déficit de Evapotranspiração Potencial Relativo e Índice de Comprometimento com a Poluição.

Pesquisas recentes indicam que a água deste rio encontra-se em um acelerado processo de eutrofização, destacando a série nitrogenada $\left(\mathrm{N}^{-\mathrm{NO}_{3}}, \mathrm{~N}_{-} \mathrm{NO}_{2}^{-}\right.$e N-NH$\left.{ }_{3}\right)$ como um dos principais contaminantes [1]. Contudo, a quantificação destes compostos por si só não é suficiente para estabelecer uma relação direta com suas biodisponibilidades, advindas das constantes descargas de efluentes e da oxidação de matéria orgânica (MO), 
mostrando a necessidade de estudos mais detalhados de forma a auxiliar no manejo adequado dos recursos disponíveis nesta bacia.

Nesse sentido, parâmetros físico-químicos, tais como o potencial hidrogeniônico $(\mathrm{pH})$, temperatura $(\mathrm{T})$, potencial de oxidação e redução $(\mathrm{Eh})$ e oxigênio dissolvido (OD) são essenciais, uma vez que alterações destes parâmetros resultam na variação das diversas formas de nitrogênio, que podem atingir concentrações tóxicas para peixes, zooplânctons, algas e para o próprio homem, por sua ligação com alguns tipos de câncer, mutações, anomalias e algumas vezes, até a morte de fetos (metemoglobinemia) por hipoxia e cianose [3$15]$.

No entanto, pouquíssimos trabalhos relacionam a série nitrogenada com estes parâmetros. A grande maioria dos autores tem centrado seus estudos em mostrar aspectos patogênicos e toxicológicos dos derivados do nitrogênio no corpo aquático [16-19] ou simplesmente quantificá-los para fins de diagnóstico e monitoramento. Dentre os mais recentes publicados no Brasil, Cabral e colaboradores [20], estudando os teores de nitrato e amônio nas águas do Aqüífero Barreiras, nos bairros do Reduto, Nazaré e Umarizal, na cidade de Belém/PA, mostraram que fatores antrópicos tem maior influência na evolução dos teores de nitrato e amônio, nessas águas, que os sazonais.

Simões [21] estudou o efeito da piscicultura em sistemas aquáticos nas cidades de Assis e Cândido Mota, no Estado de São Paulo, utilizando o Índice de Qualidade da Água (IQA) e Análise Estatística Multivariada, com aplicação da Análise por Componentes Principais (ACP). Os resultados mostraram que em locais onde essa atividade econômica predomina, o IQA é $\geq 52$, indicando uma boa qualidade da água, enquanto que a ACP indicou uma má qualidade para estes corpos aquáticos. Ainda neste estudo, os autores mostraram a necessidade inerente do desenvolvimento de IQAs específicos para cada recurso hídrico e que excluam efeitos indesejáveis nos quais um parâmetro físico-químico mascare o efeito de outro.

Além destes, ao fazer um estudo da geoquímica das águas da bacia hidrográfica do rio Descoberto, Brasília/DF, por meio de um tratamento estatístico não paramétrico, através da correlação de Spearman, Carmo [4] pôde avaliar, através de parâmetros físico-químicos, as possíveis fontes de contaminação e suas conseqüências a médio e longo prazo, devido ao processo de urbanização desordenada e utilização indiscriminada de fertilizantes em áreas agrícolas.

Da mesma forma, em relação à bacia hidrográfica Apodi/Mossoró, não existem estudos que contemplem essa discussão, dificultando a compreensão dos equilíbrios que envolvem o nitrogênio neste ecossistema e, conseqüentemente, o planejamento de ações sustentáveis para a região.

Deste modo, este trabalho tem por objetivo correlacionar as concentrações de $\mathrm{NO}_{3}^{-}, \mathrm{NO}_{2}^{-}$e $\mathrm{NH}_{3}$ com os valores de $\mathrm{pH}, \mathrm{T}$, Eh e OD na bacia hidrográfica Apodi/Mossoró.

\section{MATERIAL E MÉTODOS}

\section{Coleta e preservação das amostras}

Foram selecionadas 24 estações de amostragem, distribuídas em toda a extensão do rio, as com auxílio de GPS, em 07/2007, com posteriores coletas trimestrais (08 e 11/2007 e 02/2008). A escolha dos pontos levou em consideração a presença de atividades antrópicas no entorno do rio.

As amostras foram coletadas a uma profundidade de aproximadamente $30 \mathrm{~cm}$ da superfície, em frascos de vidro, e armazenadas em caixas de isopor contendo gelo e transportadas para o laboratório, onde foram acondicionadas em um refrigerador a uma temperatura de aproximadamente $4^{\circ} \mathrm{C}$.

\section{Análise dos parâmetros Físico-químicos}

As medidas de $\mathrm{pH}, \mathrm{T}$, Eh e OD foram realizadas in loco, utilizando um medidor multiparamétrico de marca ORION, modelo 5 STAR.

Os ensaios de $\mathrm{N}_{-} \mathrm{NO}_{3}^{-}, \mathrm{N}-\mathrm{NO}_{2}^{-}$e do N-NH foram feitos em triplicata, utilizando-se reagentes PA e um espectrofotômetro UV-visível, de marca SHIMADZU. O N-NO ${ }_{3}^{-}$foi determinado pelo método ultravioleta, com pré-tratamento por suspensão de hidróxido de alumínio; o $\mathrm{N}_{-} \mathrm{NO}_{2}^{-}$, a partir da reação com a sulfanilamida e o bicloridrato de 
naftiletilenodiamina, em meio ácido e o $\mathrm{N}-\mathrm{NH}_{3}$ foi quantificado pelo método do fenato, baseado na reação com hipoclorito e fenol, catalisada por nitroprussiato [22].

Neste trabalho, sempre que se referir a $\mathrm{N}_{-} \mathrm{NH}_{3}$ deve-se considerar as duas formas de nitrogênio amoniacal $\left(\mathrm{N}-\mathrm{NH}_{4}{ }^{+} \mathrm{e} \mathrm{N}-\mathrm{NH}_{3}\right)$, como proposto por Esteves [23], uma vez que o meio oscila entre o levemente ácido e o alcalino.

\section{RESULTADOS E DISCUSSÃO}

Devido aos elevados índices de evaporação e baixa pluviosidade, não foi encontrada água no ponto 1 em nenhuma das três coletas e no ponto 6 , na segunda coleta.

Analisando os resultados das concentrações de $\mathrm{NO}_{3}^{-}, \mathrm{NO}_{2}^{-}$e $\mathrm{NH}_{3}$ (Figura 3), pode-se observar que os íons nitrato apresentam teores mais elevados, seguido pelo nitrito e amônia. Em relação aos teores de nitrato, destacam-se os pontos 5, 15 e de
20 a 24; aos de nitrito, os pontos 5 e 14 e aos de amônia, o ponto 5. Vale salientar que os pontos 5 (Pau dos Ferros), 14, 15 e 20 (Mossoró) estão localizados nos maiores centros urbanos banhados pelo rio, onde são lançados efluentes domésticos e industriais sem qualquer tratamento prévio, além da criação de animais em seu entorno. Somado a isto, os pontos 14 e 15 estão situados em um canal de desvio do rio que se encontra interrompido, formando uma lagoa de decantação. Já os pontos 21 a 24 abrangem a região de estuário e onde se concentram atividades de carcinicultura e salineira.

É difícil prever o impacto ambiental resultante do despejo de certas substâncias no meio aquático, em virtude dos processos sinérgicos característicos a cada descarga (defensivos agrícolas, detergentes sintéticos, presença de óleo e graxas, dentre outros). Contudo, as condições de Eh, $\mathrm{OD}, \mathrm{pH}$ e T regulam o efeito de decomposição de matéria orgânica (mineralização do nitrogênio), nitrificação e desnitrificação [6, 12, 23].

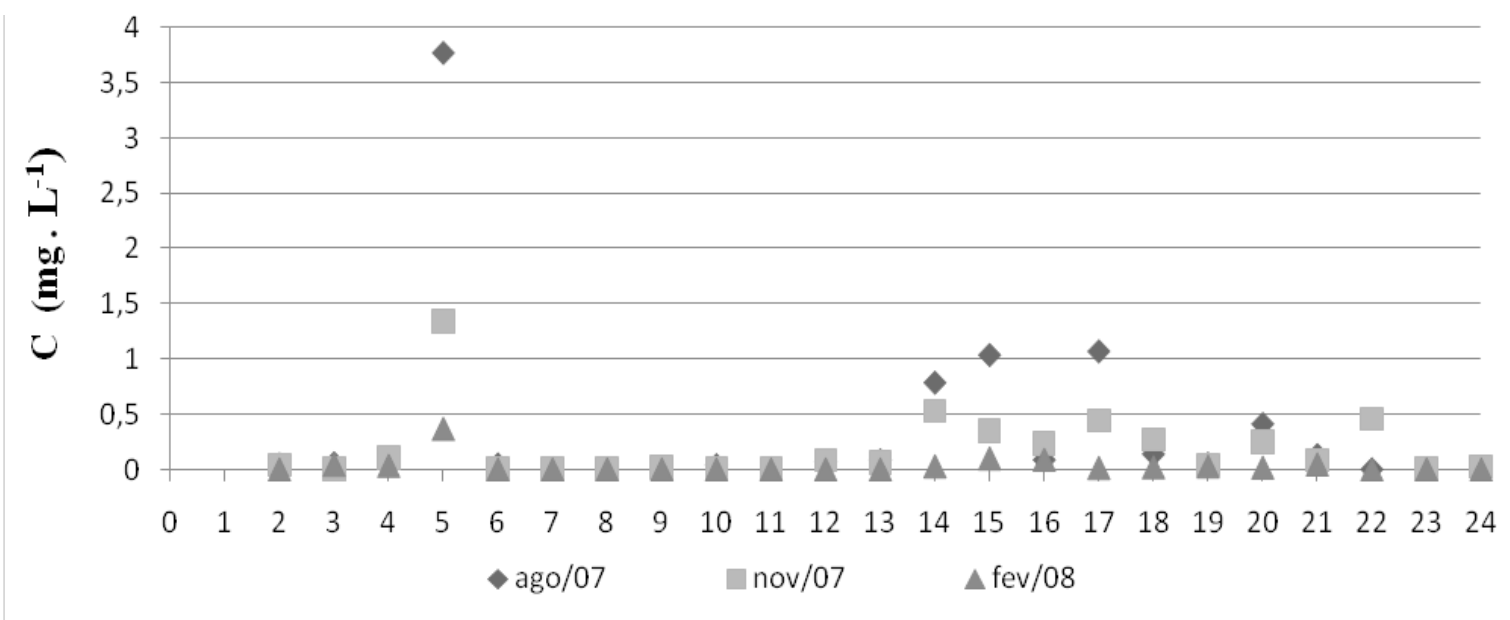

(C)

Figura 3 - Teores de $\mathrm{NO}_{3}^{-}(\mathrm{A}) ; \mathrm{NO}_{2}^{-}(\mathrm{B})$ e $\mathrm{NH}_{3}(\mathrm{C})$ nos diversos pontos de amostragem da Bacia Hidrográfica Apodi/Mossoró. 


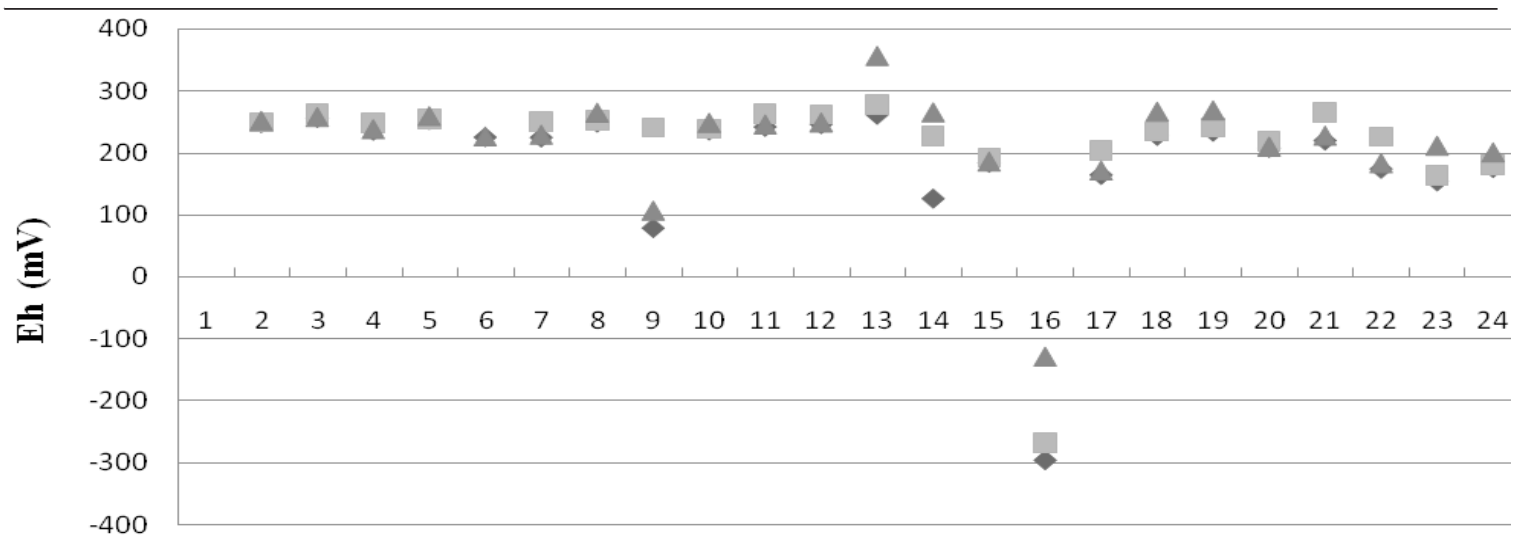

Pontos de Coleta

$\bullet \mathrm{ago} / 07 \square$ nov/07 $\Delta \mathrm{fev} / 08$

Figura 4 - Valores de Eh nos diversos pontos de amostragem da Bacia Hidrográfica Apodi/Mossoró.

Correlação entre a série nitrogenada e o Eh do meio

Em relação ao Eh, analisando a Figura 4 pode-se observar que em praticamente todo o rio foram obtidos valores elevados $(226,7 \pm 43,7)$, nas três campanhas de coleta, com exceção do ponto 16. Valores altos de Eh estão relacionados com o meio oxidante, indicando a presença de nitrogênio, principalmente na forma de $\mathrm{NO}_{3}^{-}$, enquanto que os baixos indicam o meio redutor e, neste caso, a presença de espécies como $\mathrm{NH}_{3}$ e $\mathrm{NH}_{4}^{+}$[24]. No entanto, a Figura 3 mostra altas concentrações de nitrato e baixas concentrações de amônia neste ponto. Segundo Braga e colaboradores [25], isto ocorre quando o consumo de OD é mais intenso que a capacidade de reposição, fazendo com que parte da matéria orgânica seja decomposta por processos anaeróbicos, constatado, neste caso, pela presença de $\mathrm{NH}_{3}$ no meio.

Por outro lado, concomitantemente, a $\mathrm{MO}$ suspensa e/ou retida no sedimento pode estar sendo assimilada por microorganismos aeróbicos, que utilizam o OD como veículo para decomposição da mesma, disponibilizando espécies oxidadas $\left(\mathrm{NO}_{2}^{-} \mathrm{e}\right.$, principalmente, $\left.\mathrm{NO}_{3}^{-}\right)$para o meio. Este comportamento está em concordância com o valor de OD medido no momento da coleta, que se apresentou muito baixo, variando de 0,1 a $1,3 \mathrm{mg}$
$\mathrm{L}^{-1}$. Além disso, o ponto 16 está localizado em um canal artificial, onde o fluxo de água é muito baixo, diminuindo a vazão até tornar-se praticamente nula no período de seca, que associado às grandes descargas de efluentes in natura, torna o processo de depleção de oxigênio ainda mais intenso.

Outro dado importante a ser considerado neste estudo é que, quanto maior a perda de água no período de estiagem, que ocorre, principalmente, por evaporação, maior o valor de Eh, constatado pelo aumento consecutivo deste parâmetro nas três campanhas em $52,2 \%$ dos pontos em que foi medido. 


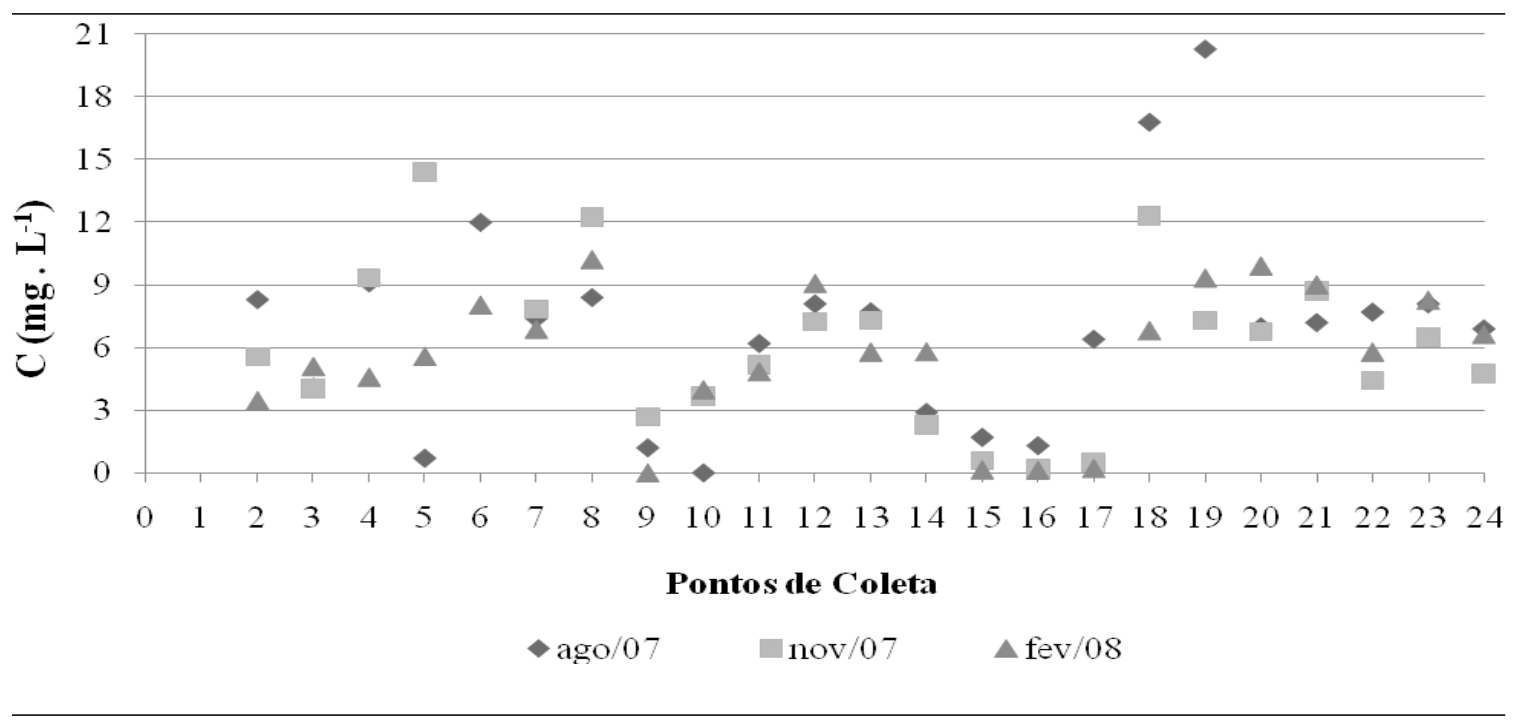

Figura 5 - Variação de OD nos diversos pontos de amostragem da Bacia Hidrográfica Apodi/Mossoró.

Correlação entre a série nitrogenada e a disponibilidade de $O D$

Conforme Figura 5, os valores de OD medidos nos diversos pontos de coleta apresentaram, no geral, grande oscilação. Provavelmente, o fato destas medidas não serem realizadas no mesmo horário, associado às elevadas temperaturas da água no momento da coleta $\left(28,5^{\circ} \mathrm{C} \pm 2,7\right)$, tenham contribuído significativamente para esta variação, a ponto de se obter desde valores infinitesimalmente baixos (não detectados) a bastante significativos $(20,3 \mathrm{mg} / \mathrm{L})$, dificultando, inclusive, sua correlação com outras variáveis na massa d'água. Estes resultados estão em conformidade com as observações de vários autores para outros corpos aquáticos [23, 27-30].

Tomando-se como referência os valores citados na literatura, para a concentração mínima de oxigênio dissolvido necessária a vida aquática $[6,12]$, os pontos 5 (Pau dos Ferros), 9 (Lagoa de Apodi), 10 (município de Governador Dix-Sept Rosado), 14, 15, 16 e 17 (centro urbano de Mossoró) podem ser considerados críticos, por apresentarem baixíssimos níveis de OD. Isso ocorre, possivelmente, devido ao processo de decomposição da MO [25], que juntamente com a estratificação térmica, causada, principalmente, pela ausência de cobertura ciliar, permite que a radiação solar incida diretamente sobre a água, fazendo com que o nível de oxigênio dissolvido diminua drasticamente, tendo em vista que a solubilidade dos gases diminui com o aumento da temperatura [23].

Por outro lado, como mostra a Figura 5, foram detectadas concentrações elevadas nos pontos 5 (Pau dos Ferros), 18 e 19 (região urbana de Mossoró) durante a primeira campanha de coleta. Em todo o centro urbano destas cidades foi observada uma grande quantidade de macrófitas aquáticas (aguapés), além de uma variedade de algas que atribui uma cor verde e limosa ao rio. Deste modo, no início da tarde, horário em que as coletas nestes pontos foram efetuadas, a produção de oxigênio via fotossíntese é significativa, podendo chegar a valores bastante elevados. Estes dados complementam a discussão relacionada ao Eh, que indica o predomínio de espécies oxidadas no meio, neste caso o $\mathrm{NO}_{3}^{-}$, que está diretamente relacionada com a proliferação acentuada de plantas aquáticas, juntamente com o fósforo, outro nutriente essencial à planta.

Correlação entre a série nitrogenada e o $\mathrm{pH} / \mathrm{T}$

Observando a Figura 6, percebe-se que o $\mathrm{pH}$ variou de 7,0 a 9,2, a uma temperatura média de $28,5^{\circ} \mathrm{C}$, exceto para o ponto 12 (Barragem do 
Genésio), na $2^{\mathrm{a}}$ coleta, quando observou-se queda significativa no valor. Este ponto está situado ao lado de um anel viário da BR 304, que dá acesso ao perímetro urbano de Mossoró, onde o fluxo de automóveis, caminhões de carga e motocicletas é constante e, conseqüentemente, a emissão de $\mathrm{CO}_{2}$ é significativa. Este gás, ao se dissolver na água, forma o ácido carbônico $\left(\mathrm{H}_{2} \mathrm{CO}_{3}\right)$, reduzindo o $\mathrm{pH}$ do meio, conforme dados relatados por Braga et. al. [25], que obteve um valor de pH igual a 5,6 em águas saturadas de gás carbônico $\left(\mathrm{CO}_{2}\right)$.

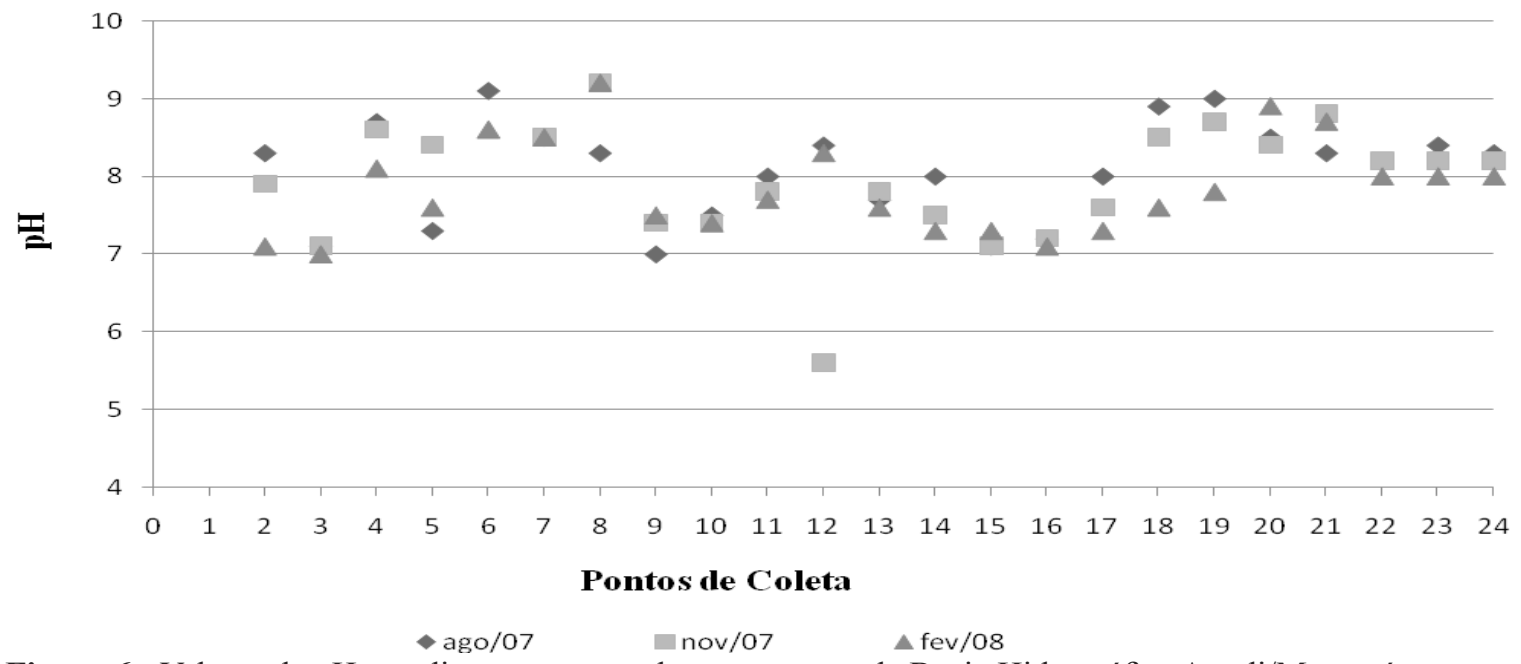

Figura 6 - Valores de pH nos diversos pontos de amostragem da Bacia Hidrográfica Apodi/Mossoró.

Além disso, organismos heterotróficos (bactérias e animais aquáticos) atuam sobre o valor do $\mathrm{pH}$ abaixando-o, em virtude dos intensos processos de respiração e decomposição, que libera $\mathrm{CO}_{2}(\mathrm{~g})$ na massa d'água, com conseqüente formação de $\mathrm{H}_{2} \mathrm{CO}_{3}$ e íons hidrogênio $\left(\mathrm{H}^{+}\right)$. Outros processos metabólicos que ocorrem em águas naturais também contribuem para o abaixamento do $\mathrm{pH}$ do meio como a troca iônica, hidrólise de cátions e ácidos orgânicos e inorgânicos que se dissociam liberando $\mathrm{H}^{+}$[23].

Ambientes ricos em biomassa vegetal também estão sujeitos a variações de pH [23]. Durante todo o período de estiagem desta bacia, foram encontradas densas comunidades de macrófitas aquáticas no ponto 3 (Riacho de Santana), 5, 9 e do 12 ao 19. Assim, podem ocorrer padrões e amplitudes diferenciadas de variação desta propriedade, durante o ciclo diário no ecossistema e até em diferentes locais deste mesmo meio.

$\mathrm{O}$ pH básico, em grande parte dos pontos avaliados, faz com que o íon amônio se transforme em amoníaco, $\mathrm{NH}_{3(\mathrm{~g})}$, sendo posteriormente eliminado por evaporação, devido às elevadas T. Isso pode justificar os baixos níveis de $\mathrm{NH}_{3}$ em toda a extensão do rio, que associado ao processo de nitrificação e a decomposição aeróbia da matéria orgânica, resultou no aumento da concentração de $\mathrm{NO}_{3}^{-}$. Vale salientar que a nitrificação das formas amoniacais também pode estar diretamente ligada às oscilações obtidas nas concentrações de OD.

Outro ponto importante, destacado por Trussel [30], é que ambientes em que se tem elevados valores de $\mathrm{pH}(>9,0)$ e $\mathrm{T}\left(>26^{\circ} \mathrm{C}\right)$, e baixos de Eh, a amônia pode atingir níveis letais a uma grande diversidade de seres aquáticos. Em nenhum dos pontos analisados atingiu-se estes três critérios simultaneamente, mas em todos eles pode ser identificado que pelo menos dois destes parâmetros estão em conformidade com esta observação, o que classifica a área como passível de ameaça a vida aquática.

De acordo com a lei $\mathrm{n}^{\circ} 357 / 2005$, do CONAMA [31], considerando o rio como sendo de Classe 2, foram detectados 3 pontos $(5,15$ e 21) com valores acima do permitido (VAP) para o $\mathrm{NO}_{3}{ }^{-}$na $1^{\mathrm{a}}$ coleta, 6 pontos $(5,15,20,22,23$ e 24) na $2^{\mathrm{a}}$ e 1 ponto (15) na $3^{\mathrm{a}}$ coleta. Para o $\mathrm{NO}_{2}^{-}$, apenas o ponto 14 na $1^{\text {a }}$ coleta apresentou VAP. 
No caso da $\mathrm{NH}_{3}$, nenhum dos pontos apresentou VAP pela legislação.

Complementando a discussão anterior, que pode justificar este panorama, é importante lembrar que o sedimento de fundo é um importante compartimento de estocagem de nutrientes no corpo aquático, que pode estar biodisponibilizando espécies adsorvidas, tendo em vista o longo período de exposição do mesmo a diversos sais minerais provenientes de esgotos lançados in natura.

\section{CONCLUSÕES}

Além dos dados quantitativos trabalhados, as observações feitas in loco mostram a relação existente entre a biodisponibilidade de $\mathrm{NO}_{3}^{-}, \mathrm{NO}_{2}^{-}$ e $\mathrm{NH}_{3}$ nas águas do rio e os valores dos demais parâmetros físico-químicos. Estes, associados à vulnerabilidade do semi-árido potiguar e a grande diversidade de atividades antrópicas em toda a extensão do rio, contribuem de forma bem expressiva no aceleramento do seu processo de eutrofização.

Vale ressaltar a importância do desenvolvimento de pesquisas voltadas ao monitoramento e diagnóstico ambiental, para fortalecer as bases científicas na área, já que a literatura disponível ainda é escassa quando se trata da correlação dos parâmetros que atribuem qualidade às águas, permitindo deste modo, a adoção de medidas mitigadoras de controle e manejo das fontes poluidoras.

Behavior of nitrogen series in the waters of the Apodi/Mossoró basin - RN - Brazil

\begin{abstract}
The Apodi/Mossoró basin is one of the most important water resources in the state of Rio Grande do Norte. Recent studies have shown that nitrogen compounds stand out among the river's main contaminants. There is thus a need to relate their presence to other physicochemical properties that influence their formation. This paper aims to correlate the concentrations of $\mathrm{NO}_{3}^{-}, \mathrm{NO}_{2}^{-}$and $\mathrm{NH}_{3}$ with the values of $\mathrm{pH}, \mathrm{T}, \mathrm{Eh}$ and $\mathrm{DO}$ in the waters of this basin. The results indicate the predominance of a strongly oxidizing environment, highlighting $\mathrm{NO}_{3}^{-}$as the main form of nitrogen present, even in places where significant reductions in Eh and OD were observed. This paper gives a contribution for the development of control and treatment of sources of pollution and better management of water resources.
\end{abstract}

Keywords: River Apodi /Mossoró, eutrophication, physicochemical properties, nitrogen, water.

\section{REFERÊNCIAS BIBLIOGRÁFICAS:}

[1] D. F. F. Martins, R. B. Souza, T. M. B. F. Oliveira, L. D. Souza, S. S. L. Castro, Revista Química no Brasil 2 (1) (2008) 61.

[2] A. C. Rebouças, B. Braga, J. G. Tundisi (Org.), Águas doces no Brasil: capital ecológico, uso e conservação, Escrituras Editora, São Paulo, 1999, cap. 15.

[3] E. M. Richter, A. Fornaro, C. L. L. L. Angnes, Quím. Nova 30 (5) (2007) 1147.

[4] M. S. Carmo, G. R. Boaventura, E. C. Oliveira, Quím. Nova 28 (4) (2005) 565.

[5] D. M. C. Guiraud, E. Lenzi, E. B. Luchese, L. O. B. Fávero, Braz. Arch. Biol. Technol. 47 (4) (2004).

[6] C. Baird, Química Ambiental, Bookman, Porto Alegre , $2^{\text {a }}$ ed., 2002, cap. 8.

[7] P. Drechsel, L. Gyele, D. Kunze, O. Cofie, Ecol. Econ. 38 (2001) 251.

[8] A. R. Carvalho, F. H. M. Schlittler, V. L. Tornisielo, Quim. Nova 23 (5) (2000) 618.
[9] R. C. B. Andrade, M. F. L. Souza, E. C. G. Couto, Quím. Nova 21 (4) (1998) 424.

[10] R. M. Doborow, D. M. Crosby, M. W. Brunson, Ammonia in fish ponds. Southern Regional Aquaculture Center, [S. L.], (463) (1997).

[11] A. V. L. Bittencourt, Bol. Paraná. Geociênc. 35 (1996) 1.

[12] J. C. Rocha, A. H. Rosa, A. A. Cardoso, Introdução à Química Ambiental, Bookman, Porto Alegre, 2004, cap. 2.

[13] A. N. Jaworski, P. M. Groffman, A. A. J. C. Keller, J. C. Prager, Estuaries 15 (1) (1992) 83.

[14] P. Sequi, C. Ciavatta, L. V. Antisari, Agrochimica 35 (13) (1991) 200 .

[15] B. A. Rosenteel, P. F. Strom, Water Resour. Bull. 27 (6) (1991) 957.

[16] S. W. Chung, P. W. Gassman, D. R. Huggins, G. W. Randall, J. Environ. Qual. 30 (3) (2001) 822.

[17] J. Wu, B. A. Babcock, J. Environ. Qual. 28 (1999) 1916. 
[18] A. A. Avery, Environmental Health Perspectives 107 (7) 1999.

[19] J. K. Böhlke, S. J. Mroczkowski, T. B. Coplen, Rapid Communications in Mass Spectrometry 17 (16) (2003) 1835.

[20] N. M. T. Cabral, Quím. Nova 30 (8) (2007) 1804.

[21] F. S. Simões, M. J. S. Yabe, A. B. Moreira, M. C. Bisinoti, Quim. Nova 30 (8) (2007) 1835.

[22] M. C. Rand, A. G. Greemberg, M. J. Taraj, (Ed.), Standard Methods for the Examination of Water and Wastewater, American Public Heath Association/American Water Works Association/Water Pollution Control Federation, Washington, 20th ed., 1998. Parth 4500.

[23] F. A. Esteves, Fundamentos de Limnologia, Interciência, Rio de Janeiro, 1988, cap. 10-13.

[24] Alloway, B. J. Heavy Metals in Soils, Blackie Academic \& Professional, New York, 1993, chap. 2.

[25] B. Braga, I. Hespanhol, J. G. L. Conejo, J. C. Mierzwa, M. T. L. Barros, M. Spencer, M. Porto, N. Nucci, N. Juliano, S. Eiger, Introdução à Engenharia Ambiental: o desafio do desenvolvimento sustentável, Pearson Prentice Hal, São Paulo, $2^{\mathrm{a}}$ ed., 2005, cap. 8 .

[26] A. F. M. Camargo, R. K. Miyai, Acta Limnologica Brasiliensia 11 (1988) 153.

[27] J. M. Melack, R. T. Fisher, Archiv fur Hydrobiologie 98 (4) (1983) 422.

[28] E. Idelovitch, M. Michail, Journal of the water pollution control federation 53 (9) (1981) 1391.

[29] P. J. A. Withers, E. I. Lord, Sci. Total Environ., 23 (2002) 9.

[30] R. P. Trussel, J. Fish. Res. Board. Can., 29 (1972) 1505. [31] Conselho Nacional de Meio Ambiente, Resolução no 357 de 18 de março de 2005. Dispõe sobre a classificação das águas no Brasil. 